\title{
Socio-Demographic Characteristics and Risk Factors Contributing Pulmonary Tuberculosis Infection and Recent Transmission
}

\author{
S. M. Shahriar Rizvi', Shirin Tarafder ${ }^{2}$, S. M. Mostofa Kamal ${ }^{3}$, Shaheda Anwar ${ }^{4}$, \\ Fatima Tuj Johora ${ }^{5}$, Shamim Hossain ${ }^{6}$ \\ ${ }^{1}$ Communicable Disease Control, Directorate General of Health Services, Dhaka, Bangladesh \\ ${ }^{2}$ Department of Microbiology and Immunology, Bangabandhu Sheikh Mujib Medical University, Dhaka, Bangladesh \\ ${ }^{3}$ National Tuberculosis Reference Laboratory, NIDCH, Dhaka, Bangladesh \\ ${ }^{4}$ Department of Microbiology and Immunology, Bangabandhu Sheikh Mujib Medical University, Dhaka, Bangladesh \\ ${ }^{5}$ Department of Microbiology, East West Medical College, Dhaka, Bangladesh \\ ${ }^{6}$ Medical Technologist, National Tuberculosis Reference Laboratory, NIDCH, Dhaka, Bangladesh \\ Email: shahriarrizvi@gmail.com
}

How to cite this paper: Shahriar Rizvi, S.M., Tarafder, S., Mostofa Kamal, S.M., Anwar, S., Johora, F.T. and Hossain, S. (2019) Socio-Demographic Characteristics and Risk Factors Contributing Pulmonary Tuberculosis Infection and Recent Transmission. Journal of Tuberculosis Research, 7, 228-237.

https://doi.org/10.4236/jtr.2019.74022

Received: September 12, 2019

Accepted: December 2, 2019

Published: December 5, 2019

Copyright $\odot 2019$ by author(s) and Scientific Research Publishing Inc. This work is licensed under the Creative Commons Attribution International License (CC BY 4.0).

http://creativecommons.org/licenses/by/4.0/

\section{cc) (i) Open Access}

\begin{abstract}
Host factors, environmental factors, genetic diversity and distinct phylogeographic distribution of Mycobacterium tuberculosis (MTB) contribute to regional differences in drug resistance. Bangladesh remains among the top 20 high Multi drug resistant tuberculosis (MDR-TB) burden countries of the world. This cross sectional study was conducted to identify the socio demographic characteristics and the risk factors contributing Pulmonary tuberculosis (PTB) infection. These characteristics and risk factors were further investigated among the clustered isolates. Total 60 culture isolates consist of 40 $\mathrm{RR}$ and 20 rifampicin sensitive (RS) isolates were enrolled in this study. Laboratory works were done in National Tuberculosis Reference Laboratory (NTRL) and Department of Microbiology, Bangabandhu Sheikh Mujib Medical University (BSMMU), Dhaka, Bangladesh. All 60 samples were confirmed as MTB by MPT 64 antigen detection. Two samples were excluded for possible cross contamination and two for failing to give PCR product for most of the locus. So, finally 56 samples were further analyzed for results. Four isolates were distributed within two clusters which were belonged to Beijing lineage. Socio demographic data and risk factors analysis of this study found significant male predominance $(\mathrm{p}=0.04)$ with history of smoking $(\mathrm{p}=$ $0.01)$ and previous anti-TB treatment $(\mathrm{p}=0.012)$ as the significant risk factors for RR TB.
\end{abstract}




\section{Keywords}

Tuberculosis, Socio-Demographic, Beijing, Lineage, Epidemiology

\section{Introduction}

Drug-resistant Tuberculosis (TB) threatens global TB care and prevention, and remains a major public health concern in many countries. Globally in 2016, an estimated $4.1 \%$ of new cases and $19 \%$ of previously treated cases had MDR/Rifampicin resistant TB (RR-TB) [1]. MDR-TB is TB that is resistant to both rifampicin and isoniazid. Both MDR \& RR-TB require treatment with second-line drugs. In 2015, the incidence of MDR/RR-TB was $6 / 100,000$ population in Bangladesh. Distribution of MDR/RR-TB was $1.6 \%$ in new cases of TB and $29 \%$ in previously treated cases of TB in 2015. In the same year, total estimated cases of MDR/RR-TB were 5100 [2] [3]. MDR-TB can occur via two mechanisms: through the selection of resistant $M$. tuberculosis bacilli during poorly managed anti-TB treatment or via direct transmission from an infectious patient to another. The risk of drug resistance is higher among TB patients who have previously received anti TB chemotherapy. Early studies suggested that effective treatment of drug-susceptible TB would prevent the emergence of resistance [4]. Some studies suggested that failure to diagnose and treat MDR-TB might result in "hot spots" of disease [5].

By incorporating molecular biology methods, epidemiological studies have reached the molecular level. Molecular epidemiology has emerged from a combination of genotyping techniques and conventional epidemiological approaches. This new discipline has established as a resource for understanding the issues in the epidemiology of TB. It comprises sources of infection, to quantify recent transmission, linking transmission and factors for transmission, to evaluate reinfection from relapse. It also tracks the geographic distribution, clonal expansion of strains [6] and helps to identify major clones in association with multidrug resistance [7].

The Mycobacterium tuberculosis Complex (MTBC) consists of a group of highly related mycobacterial lineages (99.9\% nucleotide identity). This Complex comprises obligate human pathogens Mycobacterium tuberculosis sensustricto and Mycobacterium africanum. The geographical spread of these lineages differs markedly. Some lineages exhibit a global distribution and others a strong geographical restriction [8] [9].

Delays in the diagnosis and control measures can result in further spread of $\mathrm{TB}$, even among individuals who are at low risk [10]. TB transmission can be extended to social and casual contacts, which are more difficult to trace by classical epidemiological investigation [11] [12]. If asymptomatic individuals remain undetected for a prolong time, they can remain contagious and be the source of unsuspected TB outbreaks [13]. 
There are few published data regarding circulating strain typing of MTB to evaluate the relation with socio-demographic characteristic of the PTB patients in Bangladesh. This study was an effort to identify the socio-demographic characteristics and risk factors contributing recent transmission of PTB infection.

\section{Materials and Methods}

\subsection{Ethical Considerations}

Before starting this study, the research protocol was approved by the Institutional Review Board (IRB) of Bangabandhu Sheikh Mujib Medical University (BSMMU), Dhaka, Bangladesh. Permission for the study was taken from the Coordinator, National Tuberculosis Reference Laboratory (NTRL) from where study subjects were selected. Subjects were enrolled after receiving informed written consent from themselves. Assent was taken if the subject was less than 18 years of age. Data were recorded on a predesigned data sheet.

\subsection{Study Setting}

This Cross sectional observational study was conducted at Department of Microbiology \& Immunology, Bangabandhu Sheikh Mujib Medical University (BSMMU), Dhaka, Bangladesh and National Tuberculosis Reference Laboratory (NTRL), Bangladesh from March, 2017 to February, 2018. Previously tested sputum by XPert MTB/RIF assay (Cepheid, USA) showed growth for Mycobacterium tuberculosis on solid or liquid culture medium were included in this study for further analysis. So, according to this inclusion criterion, all MTB culture positive samples during this study period were included. These patients were enrolled in this study and were further interviewed for socio-demographic data and risk factors according to a predesigned data sheet which included particulars of the patients, socio-demographic characteristics, risk factors and laboratory findings. Informed written consent or assent was taken before collecting these data. The results of these socio-demographic data and risk factors are discussed in result section (see Table $1 \&$ Table 2).

At NTRL, isolates were cultured on both Lowenstein-Jensen (L-J) media and Mycobacteria Growth Indicator Tube (MGIT) and were identified as AFB by Z-N staining and as Mycobacterium tuberculosis by MPT 64 antigen test (Standard Diagnostic Inc., Korea) following standard operating procedure. Genotyping of the MTB isolates were done at BSMMU by 24 locus MIRU-VNTR analysis as described by Supply et al. [14].

\subsection{Epidemiological Investigation}

A cluster was defined as two or more isolates from different patients with identical Mycobacterial Interspersed Repetitive Unit (MIRU) patterns, whereas nonclustered patterns were regarded as unique. Cluster indicates the recent transmission from the same source of infection. Clustered samples were further investigated for direct epidemiological linkage. 
Table 1. Socio-demographic data and risk factors of study population $(n=56)$.

\begin{tabular}{|c|c|c|c|c|c|}
\hline \multirow[b]{2}{*}{ Categories } & \multirow[b]{2}{*}{ Sub categories } & \multirow{2}{*}{$\begin{array}{l}\text { Total } \\
(\mathrm{n}=56) \\
\mathrm{n}(\%)\end{array}$} & \multicolumn{2}{|c|}{ Rifampicin } & \multirow[b]{2}{*}{$P$ value } \\
\hline & & & $\begin{array}{l}\text { Sensitive } \\
(\mathrm{n}=18) \\
\mathrm{n}(\%)\end{array}$ & $\begin{array}{l}\text { Resistant } \\
(\mathrm{n}=38) \\
\mathrm{n}(\%)\end{array}$ & \\
\hline \multirow[t]{2}{*}{ Sex } & Male & $41(73.2)$ & $10(55.6)$ & $31(81.6)$ & 0.04 \\
\hline & Female & $15(26.8)$ & $8(44.4)$ & $7(18.4)$ & \\
\hline \multirow[t]{6}{*}{ Age } & $15-19$ & $8(14.3)$ & $4(22.2)$ & $4(10.5)$ & 0.24 \\
\hline & $20-29$ & $19(33.9)$ & $4(22.2)$ & $15(39.5)$ & 0.2 \\
\hline & $30-39$ & $11(19.6)$ & $3(16.7)$ & $8(21.1)$ & 0.69 \\
\hline & $40-49$ & $9(16)$ & $3(16.7)$ & $6(15.8)$ & 0.93 \\
\hline & $50-59$ & $6(10.7)$ & $2(11.1)$ & $4(10.5)$ & 0.94 \\
\hline & $60-69$ & $3(5.5)$ & $2(11.1)$ & $1(2.6)$ & 0.18 \\
\hline \multirow[t]{2}{*}{ Location } & Urban & $50(89.3)$ & $14(77.8)$ & $36(94.7)$ & 0.055 \\
\hline & Rural & $6(10.7)$ & $4(22.2)$ & $2(5.3)$ & \\
\hline \multirow[t]{5}{*}{ Occupation } & Service & $13(23.2)$ & $4(22.2)$ & $9(23.7)$ & 0.9 \\
\hline & Business & $11(19.7)$ & $3(16.7)$ & $8(21.1)$ & 0.6 \\
\hline & Housewife & $5(8.9)$ & $2(11.1)$ & $3(7.9)$ & 0.6 \\
\hline & Student & $6(10.7)$ & $2(11.1)$ & $4(10.5)$ & 0.9 \\
\hline & Self-employed & $21(37.5)$ & $7(38.9)$ & $14(36.8)$ & 0.88 \\
\hline \multirow{3}{*}{$\begin{array}{l}\text { H/O living } \\
\text { outside } \\
\text { Bangladesh }\end{array}$} & Yes & $4(7.1)$ & $2(12.5)$ & $2(5.3)$ & 0.42 \\
\hline & & & & & \\
\hline & No & $52(92.9)$ & $16(87.5)$ & 36 (94.7) & \\
\hline \multirow[t]{2}{*}{$\begin{array}{l}\text { BCG vaccine } \\
\text { mark }\end{array}$} & Present & $53(94.6)$ & $17(94.4)$ & $36(94.7)$ & 0.9 \\
\hline & Absent & $3(5.4)$ & $1(5.6)$ & $2(5.3)$ & \\
\hline \multicolumn{6}{|l|}{ Risk factors } \\
\hline \multirow[t]{2}{*}{$\mathrm{H} / \mathrm{O} \mathrm{TB}$ contact } & Yes & $6(10.7)$ & $3(16.7)$ & $3(7.9)$ & 0.32 \\
\hline & No & $50(89.3)$ & $15(83.3)$ & & $35(92.1)$ \\
\hline \multirow[t]{2}{*}{$\begin{array}{l}\mathrm{H} / \mathrm{O} \text { Anti-TB } \\
\text { treatment }\end{array}$} & New & $11(19.6)$ & $7(38.9)$ & $4(10.5)$ & 0.012 \\
\hline & $\begin{array}{l}\text { Previously } \\
\text { Treated }\end{array}$ & $45(80.4)$ & $11(61.1)$ & $34(89.5)$ & \\
\hline \multirow[t]{2}{*}{ Smoking } & Yes & $23(41)$ & $3(16.7)$ & $20(52.6)$ & 0.01 \\
\hline & No & $33(59)$ & $15(83.3)$ & $18(47.4)$ & \\
\hline \multirow[t]{2}{*}{ Alcohol Misuse } & Yes & $1(1.8)$ & 0 & $1(2.6)$ & - \\
\hline & No & $55(98.2)$ & 18 & $37(97.4)$ & \\
\hline \multirow[t]{2}{*}{ Drug Misuse } & Yes & $1(1.8)$ & 0 & $1(2.6)$ & - \\
\hline & No & $55(98.2)$ & 18 & 37 (97.4) & \\
\hline \multirow[t]{2}{*}{$\begin{array}{l}\mathrm{H} / \mathrm{O} \text { other } \\
\text { illness }\end{array}$} & Yes & $2(3.6)$ & 0 & $2(5.3)$ & - \\
\hline & No & $54(96.4)$ & 18 & $36(94.7)$ & \\
\hline
\end{tabular}


Table 2. Characteristics of Population and risk factors among clustered Patients $(n=4)$.

\begin{tabular}{|c|c|c|c|}
\hline Categories & Sub categories & Number & Percentage \\
\hline \multirow[t]{2}{*}{ Sex } & Male & 3 & 75 \\
\hline & Female & 1 & 25 \\
\hline Age & $20-29$ & 4 & 100 \\
\hline \multirow[t]{2}{*}{ Location } & Urban & 4 & 100 \\
\hline & Rural & 0 & \\
\hline Residence & Dhaka city & 4 & 100 \\
\hline \multirow[t]{3}{*}{ Occupation } & Business & 2 & 50 \\
\hline & Student & 1 & 25 \\
\hline & Self-employed & 1 & 25 \\
\hline \multirow[t]{2}{*}{$\mathrm{H} / \mathrm{O}$ living outside Bangladesh } & Yes & 0 & \\
\hline & No & 4 & 100 \\
\hline \multirow[t]{2}{*}{ BCG vaccine mark } & Present & 4 & 100 \\
\hline & Absent & 0 & \\
\hline \multirow[t]{2}{*}{$\begin{array}{l}\text { Rifampicin sensitivity pattern of the } \\
\text { isolates }\end{array}$} & Sensitive & 0 & \\
\hline & Resistant & 4 & \\
\hline \multirow[t]{2}{*}{ Lineage of the isolates } & Beijing & 4 & 100 \\
\hline & Other & 0 & \\
\hline
\end{tabular}

\section{Risk factors}

\begin{tabular}{llll} 
H/O TB contact & Yes & 0 & 100 \\
H/O Anti-TB treatment & No & 4 & 25 \\
& New & 1 & 75 \\
Smoking & Previously Treated & 3 & \\
& Yes & 0 & 100 \\
Alcohol Misuse & No & 4 & \\
& Yes & 0 & 100 \\
Drug Misuse & No & 4 & 100 \\
H/O other illness & Yes & 0 & \\
& No & 4 & 100 \\
\hline
\end{tabular}

\subsection{Data Analysis}

Data were entered and analysed with IBM SPSS ver.23 software.

\section{Results}

60 patients were enrolled in this study initially as their sputum sample showed 
the growth of MTB on culture media. Among the 60 isolates, 40 were rifampicin resistant (RR) and 20 were rifampicin sensitive (RS) which were previously diagnosed by Xpert MTB/RIF assay. Out of 60 samples 2 RS isolates were excluded for possible cross contamination and $2 \mathrm{RR}$ isolates were also excluded for failing to give PCR products. So, 56 subjects were analyzed for final results.

Data shown in Table 1 shows male were significantly higher than the female patients among the RR-TB group. Most patients were within 20 - 29 years of age group 19 (33.9\%). 60 - 69 years age group were least in number 3 (5.5\%). Urban population was greater in number $50(89.3 \%)$. Most of the patients were self-employed $21(37.5 \%)$ and BCG vaccinated 53 (94.6\%). Only 4 (7.1\%) patients gave history of living outside Bangladesh. Smoking and previous treatment of anti-TB treatment were the significant risk factors among the RR-TB population.

Among clustered 4 patients 3 (75\%) were male. All of them were between 20 29 years of age. All of them were BCG vaccinated and resided within Dhaka city. All isolates of the patients were rifampicin resistant and members of Beijing lineage. Only important risk factor was found to be previous history of anti-TB treatment among 3 out of 4 patients (Table 2).

\section{Discussions}

Population characteristics of this study indicate male predominance for RR-TB $(81.6 \%)$ in comparison with female which is significant $(\mathrm{p}=0.04)$. The highest number $(33.9 \%)$ of patients was within 20 - 29 years of age group. Most of the patients $(89.3 \%)$ resided within urban area. Higher percentage $(37.5 \%)$ of the patients was self-employed rather than other occupations. 94.6\% patients had BCG vaccine marks. Risk factor analysis indicates smoking and previous anti-TB treatment adversely affects the situation which were statistically significant $(\mathrm{p}=$ 0.01 and 0.012 respectively). Only $10.7 \%$ patients gave history of TB contacts. Those indicate, sources of infections were mostly unknown. No significant association was found with alcohol consumption, drug misuse or any other illness.

In another MDR TB patient oriented study in Bangladesh found that $75 \%$ were males and $25 \%$ were females. Age range was $12-70$ years. $44 \%$ of the patients had history of exposure to TB patient and $88 \%$ had a history of previous anti-TB treatment. MDR was significantly higher among the patients with history of anti-TB treatment $(\mathrm{p}=0.001)$. They found $52 \%$ patients as smoker. Most (56.1\%) of the study population was from rural area [15].

Banu et al. conducted a study in a slum of Dhaka and found also male predominance (61.5\%) with highest proportion (26\%) of patients between $15-24$ years of age. $96.2 \%$ patients had no history of TB contacts. Risk factor analysis showed that a higher likelihood of developing active TB was associated with smoking and previous history of anti-TB treatment in their study. They also found no significant association between TB and diabetes mellitus, exposure to TB patients, and alcohol consumption [16]. 
A study in a rural area of Bangladesh found similar findings except prevalent age group which was 46 - 60 years for most of the cases [17].

Overall, most of the previous Bangladeshi studies found more or less similar findings for socio demographic data and risk factors.

Out of 38 RR isolates, 2 clusters were found; consist of 2 isolates each. All 2 clusters were Beijing genotypes. A cluster was defined as two or more isolates from different patients with identical MIRU patterns, whereas nonclustered patterns are referred to as unique. The underlying assumption is that genotypes evolve on the same timescale as the process of disease transmission so that each cluster of isolates represents a set of cases that arose recently through transmission, but isolates that are not connected via recent transmission are different through accumulated mutations [13]. Based on this finding, recent transmission index (RTI) was found to be low as $0.105 \%$ or $10.5 \%$ by " $n$ methods" (Appendix II) [18]. Low transmission rate (6.5\%) was also found in study held in rural area of Matlab, Bangladesh [17].

A study was held by incorporating data from 6 countries of different geographic location with different MDR-TB burden ratio. The findings were that $96 \%$ of $\mathrm{TB}$ cases were due to direct transmission. The highest transmission (99\%) was estimated in Uzbekistan and lowest (48\%) was in Bangladesh though it is a country of high MDR-TB burden. The other countries were included in this study were Ethiopia, Malawi, Peru and Philippines showed the transmission rate $92 \%, 82 \%, 95 \%$ and $76 \%$ respectively [19]. In Iraq, a study found $33.6 \%$ transmission rate [20]

Low index found in the present and previous studies of Bangladesh indicates that the drug resistance TB is occurring in our area is by reactivation or acquisition rather than transmission.

The population characteristics and risk factors of clustered cases of the present study were further investigated for epidemiological linkage. Direct transmission link could not be identified through investigation. However, all of these patients resided in the different parts of Dhaka city. And all of these patient's ages were between 20 - 29 years. These factors are in favors of transmission. Dhaka city is one of the most overpopulated cities of the world. There might be chance to come in contacts of the patients unknowingly in any occasion. Others characteristics of these patients included the male predominance, all were BCG vaccinated and no apparent risk factors were found excluding anti-TB treatment. Three of them were previously treated whereas 1 was a new case. All the clustered isolates were Beijing strains.

Other previous studies in Bangladesh also could not draw any direct epidemiological linkage regarding clusters. However one of the study found clustered cases among the 19 - 40 years of age group and both of the study identified Beijing as the most predominant lineage among clustered isolates [16] [17].

In this study, all the clustered persons were found to be BCG vaccinated. It is hypothesized that the Beijing strains originated in China and disseminate to the region [21]. It is also hypothesized that mass BCG vaccination may create a se- 
lection pressure, which favors the spreading of Beijing family [22]. The fact is that, most of the South East Asian region as well as Bangladesh follow the BCG mass vaccination program.

Limitations: Due to limitation of fund, large scale study could not be done. Another limitation was that, study population was mostly from the urban areas.

However, NTRL is the only national reference laboratory for tuberculosis in Bangladesh. For further analysis most of the TB samples are sent to this laboratory from different areas of the country. The present study cases were most from urban areas. Clustering of the isolates indicates that the recent transmission was occurred only by Beijing strains and most of them were circulating in young age group. Large scale study should be launched to address the further different measures to control this hyper virulent Beijing lineage. Current study also found the previous anti-TB treatment as the significant risk factor for RR/MDR TB acquisition. In depth large scale nationwide molecular epidemiological study is required to identify the factors for the acquisition of drug resistance.

\section{Conflicts of Interest}

The authors declare no conflicts of interest regarding the publication of this paper.

\section{References}

[1] WHO (2017) Global Tuberculosis Report 2017.

[2] WHO (2017) Bending the Curve: Ending TB in the WHO South-East Asia Region.

[3] NTP (2016) Annual Report 2016. National Tuberculosis Control Programme, Bangladesh.

[4] Dye, C. and Williams, B.G. (2000) Criteria for the Control of Drug-Resistant Tuberculosis. Proceedings of the National Academy of Sciences, 97, 8180-8185. https://doi.org/10.1073/pnas.140102797

[5] Blower, S.M. and Chou, T. (2004) Modeling the Emergence of the "Hot Zones": Tuberculosis and the Amplification Dynamics of Drug Resistance. Nature Medicine, 10, 1111. https://doi.org/10.1038/nm1102

[6] Jagielski, T., Van Ingen, J., Rastogi, N., Dziadek, J., Mazur, P.K. and Bielecki, J. (2014) Current Methods in the Molecular Typing of Mycobacterium tuberculosis and Other Mycobacteria. BioMed Research International, 2014, Article ID: 645802. https://doi.org/10.1155/2014/645802

[7] Merker, M., Blin, C., Mona, S., Duforet-Frebourg, N., Lecher, S., Willery, E., et al. (2015) Evolutionary History and Global Spread of the Mycobacterium tuberculosis Beijing Lineage. Nature Genetics, 47, 242. https://doi.org/10.1038/ng.3195

[8] Gagneux, S., DeRiemer, K., Van, T., Kato-Maeda, M., De Jong, B.C., Narayanan, S., et al. (2006) Variable Host-Pathogen Compatibility in Mycobacterium tuberculosis. Proceedings of the National Academy of Sciences, 103, 2869-2873.

https://doi.org/10.1073/pnas.0511240103

[9] Gagneux, S. and Small, P.M. (2007) Global Phylogeography of Mycobacterium tuberculosis and Implications for Tuberculosis Product Development. The Lancet Infectious Diseases, 7, 328-337. https://doi.org/10.1016/S1473-3099(07)70108-1

[10] Coitinho, C., Greif, G., Robello, C., Laserra, P., Willery, E. and Supply, P. (2014) 
Rapidly Progressing Tuberculosis Outbreak in a Very Low Risk Group. European Respiratory Journal, 43, 903-906. https://doi.org/10.1183/09031936.00150413

[11] Gardy, J.L., Johnston, J.C., Sui, S.J.H., Cook, V.J., Shah, L., Brodkin, E., et al. (2011) Whole-Genome Sequencing and Social-Network Analysis of a Tuberculosis Outbreak. New England Journal of Medicine, 364, 730-739.

https://doi.org/10.1056/NEJMoa1003176

[12] Wang, W., Mathema, B., Hu, Y., Zhao, Q., Jiang, W. and Xu, B. (2014) Role of Casual Contacts in the Recent Transmission of Tuberculosis in Settings with High Disease Burden. Clinical Microbiology and Infection, 20, 1140-1145. https://doi.org/10.1111/1469-0691.12726

[13] Small, P.M., Hopewell, P.C., Singh, S.P., Paz, A., Parsonnet, J., Ruston, D.C., et al. (1994) The Epidemiology of Tuberculosis in San Francisco-A Population-Based Study Using Conventional and Molecular Methods. New England Journal of Medicine, 330, 1703-1709. https://doi.org/10.1056/NEJM199406163302402

[14] Supply, P. (2005) Multilocus Variable Number Tandem Repeat Genotyping of $M y-$ cobacterium tuberculosis. Technical Guide.

[15] Banu, S., Mahmud, A.M., Rahman, M.T., Hossain, A., Uddin, M.K.M., Ahmed, T., et al. (2012) Multidrug-Resistant Tuberculosis in Admitted Patients at a Tertiary Referral Hospital of Bangladesh. PLoS ONE, 7, e40545. https://doi.org/10.1371/journal.pone.0040545

[16] Banu, S., Rahman, M.T., Uddin, M.K.M., Khatun, R., Ahmed, T., Rahman, M.M., et al. (2013) Epidemiology of Tuberculosis in an Urban Slum of Dhaka City, Bangladesh. PLoS ONE, 8, e77721. https://doi.org/10.1371/journal.pone.0077721

[17] Banu, S., Uddin, M., Islam, M., Zaman, K., Ahmed, T., Talukder, A., et al. (2012) Molecular Epidemiology of Tuberculosis in Rural Matlab, Bangladesh. The International Journal of Tuberculosis and Lung Disease, 16, 319-326. https://doi.org/10.5588/ijtld.11.0426

[18] Glynn, J.R., Vyonycky, E. and Fine, P.E.M. (1999) Influence of Sampling on Estimates of Clustering and Recent Transmission of Mycobacterium tuberculosis Derived from DNA Fingerprinting Techniques. American Journal of Epidemiology, 149, 366-371. https://doi.org/10.1093/oxfordjournals.aje.a009822

[19] Kendall, E.A., Fofana, M.O. and Dowdy, D.W. (2015) Burden of Transmitted Multidrug Resistance in Epidemics of Tuberculosis: A Transmission Modelling Analysis. The Lancet Respiratory Medicine, 3, 963-972. https://doi.org/10.1016/S2213-2600(15)00458-0

[20] Mustafa Ali, R., Trovato, A., Couvin, D., Al-Thwani, A.N., Borroni, E., Dhaer, F.H., et al. (2014) Molecular Epidemiology and Genotyping of Mycobacterium tuberculosis Isolated in Baghdad. BioMed Research International, 2014, Article ID: 580981. https://doi.org/10.1155/2014/580981

[21] Van Soolingen, D., Qian, L., de Haas, P.E., et al. (1995) Predominance of a Single Genotype of Mycobacterium tuberculosis in Countries of East Asia. Journal of Clinical Microbiology, 33, 3234-3238.

[22] Abebe, F. and Bjune, G. (2006) The Emergence of Beijing Family Genotypes of $M y$ cobacterium tuberculosis and Low-Level Protection by Bacille Calmette-Guérin (BCG) Vaccines: Is There a Link? Clinical \& Experimental Immunology, 145, 389-397. https://doi.org/10.1111/j.1365-2249.2006.03162.x 


\section{Appendix I}

\section{DATA COLLECTION SHEET}

\begin{tabular}{lll}
\hline Serial No & $:$ & Date: \\
Registration No & $:$ & Rifampicin status: \\
\hline
\end{tabular}

1) Particulars of the patients

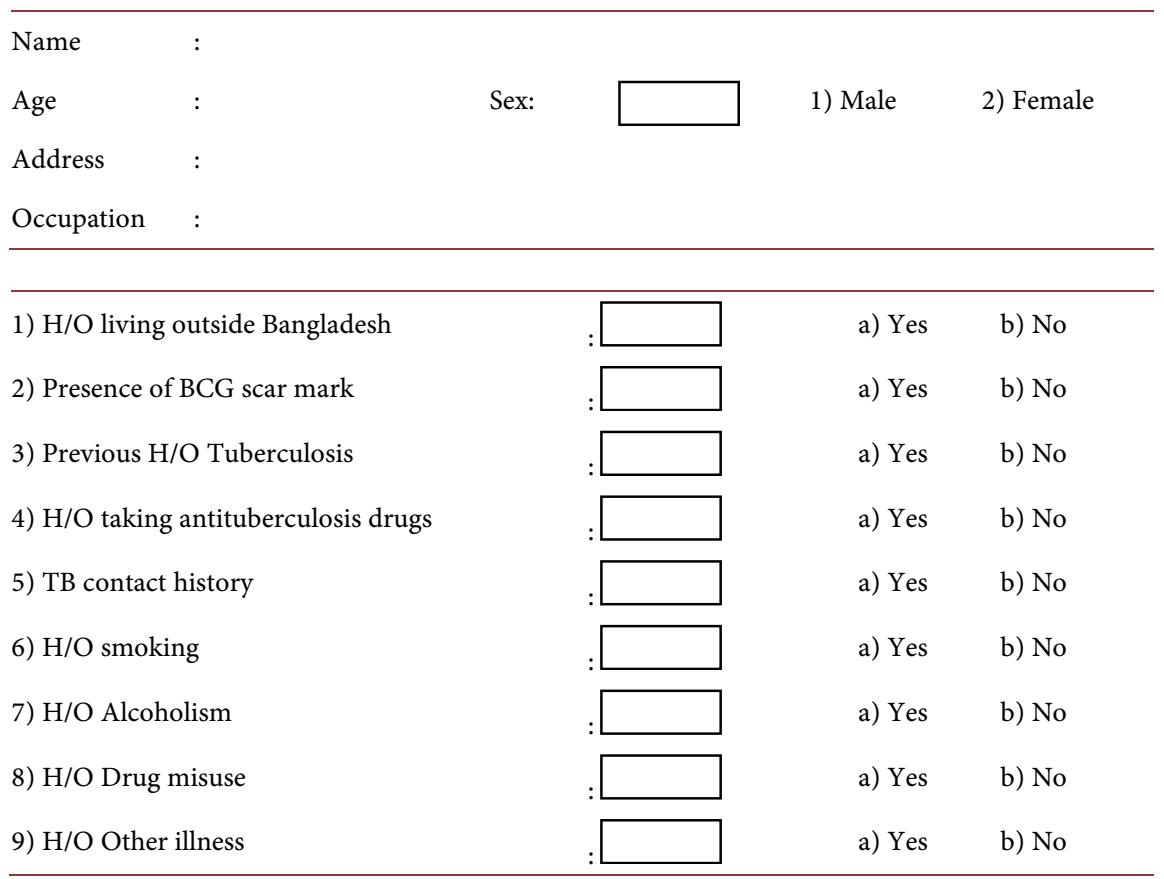

Signature of investigator.

\section{Appendix II}

\section{Recent Transmission Index:}

RTIn $=\mathrm{nc} / \mathrm{n}$

Here,

Total No. of RR isolates $=\mathrm{n}$

Total No. of clustered isolates $=\mathrm{nc}$

These indices are variable between 0 (the least recent transmission) to 1 (maximum genotypes transmission). 